\title{
Derslik Aydınlatma Performansının ve Led Armatür Uygulaması Enerji Tasarrufu Potansiyelinin Belirlenmesi Ön Çalışması
}

\author{
Selçuk SELIMLi ${ }^{1 *}$, Gözde BAKAR ${ }^{2}$, Erdoğan AYDEMIR ${ }^{2}$ \\ ${ }^{1}$ Enerji Sistemleri Mühendisliği, Teknoloji Fakültesi, Karabük Üniversitesi, Karabük, Türkiye \\ ${ }^{2}$ Enerji Verimliliği Danışmanlığı, Vat Enerji Hizmetleri San. Tic. A.Ş, İstanbul, Türkiye \\ *11 selcukselimli@karabuk.edu.tr, ${ }^{2}$ gozde.gb.bakar@gmail.com, ${ }^{2}$ ay48demir@gmail.com
}

Öz: Aydınlatma ihtiyacının konfor, sağlık, güvenlik ve yaşam kalitesi açısından değerlendirilmesi farklı ortam koşullarına özel aydınlatma sistem ve ihtiyacının varlığını ortaya koymaktadır. Eğitim alanlarının da aydınlatılması düzeyi uluslararası standartlar kapsamında belirlenmiş̦tir. Aydınlanma yanında günümüz önemli konuları arasında yer alan enerji ve maliyetleri, minimum enerji ile optimum aydınlatma ihtiyacının giderilmesi konusunda birçok araştırma geliştirme ve uygulama çalışmasının konusu durumundadır. Bu çalışma kapsamında bir eğitim kurumundaki 10 adet derslikte mevcut tüp floresan armatür ile sağlanan aydınlatma düzeyi ölçümlenmiş ve aydınlanma düzeyinin standartlarda belirtilen 300 lux düzeyinin üzerinde olduğu belirlenmiştir. Aydınlatma düzeyinin yeterli olmasına karşın gerekli aydınlatma düzeyinin mevcut armatürlerin led armatürlerle değişimi ile enerji tasarrufu sağlanabileceği değerlendirilmiștir. Gerçekleştirilecek değişim ile yıllık 8161,56 kWh enerji tasarrufu karş1lığ $3388,68 \mathrm{TL}$ olarak belirlenmiştir. $19500 \mathrm{TL}$ tutarında yatırımla mevcut armatürlerin değişimi sağlanabilmesi ve geri ödeme süresinin 5,75 yıl olması değerlendirilmektedir.

Anahtar kelimeler: Led armatür, enerji tasarrufu, aydınlatma.

\section{Preliminary Study of Determination of Classroom Lighting Performance and Led Luminaire Application Energy Saving Potential}

\begin{abstract}
Evaluation of the lighting need in terms of comfort, health, safety and quality of life reveals the existence of a lighting system and need specific to different ambient conditions. The level of illumination of the training areas is determined within the scope of international standards. In addition to enlightenment, energy and its costs, which are among the important issues of today, are the subject of many research, development and application studies in order to meet the need for optimum lighting with minimum energy. Within the scope of this study, the illumination level provided by the existing tube fluorescent luminaire was measured in 10 classrooms in an educational institution and the illumination level was determined to be above 300 lux level specified in the standards. Although the lighting level is enough, it is evaluated that the required lighting level can be saved by changing the existing luminaires with led luminaires. With the change to be realized, $8161.56 \mathrm{kWh}$ energy saving provision is determined as $3388.68 \mathrm{TL}$. It is considered that the existing luminaires can be replaced with an investment of $19500 \mathrm{TL}$ and the payback period is 5.75 years.
\end{abstract}

Key words: Led luminaire, energy saving, lightning.

\section{Giriş}

Aydınlık düzeyi farklı yaşam alanlarında konfor, güvenlik ve performansı etkileyen önemli bir olgudur. Aydınlanma ihtiyacının yoğun olduğu alanlarda enerji tüketimi de yoğunluk kazanmaktadır. Maksimum aydınlanma ihtiyacının minimum enerji girdisi ile sağlanabilmesi optimizasyonu da bu bağlamda önemlidir. Eğitim kurumları aydınlanma ihtiyacının yoğun olduğu yaşam alanlarındandır. Eğitim ortamlarında sağlanan aydınlanma düzeyi enerji tüketimi ile doğrudan ilgilidir [1]. Eğitim kurumlarında sağlanacak yeterli aydınlanma ile görsel ve ruhsal konfor, dikkat unsurunun maksimum düzeyde tutulması ile anlama performansının artırılması, çalışma ve üretkenliğinin artırılması yanında, oluşabilecek çarpma, düşme gibi kazaların önüne geçilmesi sağlanabilmektedir. Öğrenmede görsel algılama oldukça önemlidir, derslikler ve diğer çalışma alanlarında görsel konfor koşullarının sağlanması, öğrenmenin zorlanmadan, yorulmadan ve verimli bir biçimde gerçekleştirilmesi için önemli bir konudur [2]. Dersliklerin yetersiz düzeyde aydınlatılması hem çalışanlar hem de öğrencilerde baş ağrısı ve halsizlik gibi sağlık sorunlarına neden olurken, öğrenme zorluluğu ve motivasyon kaybına yol açabilmektedir [3]. Yaşam alanlarında konfor, sağlık, güvenlik ve motivasyon performansı açısından sağlanması

\footnotetext{
* Sorumlu yazar: selcukselimli@karabuk.edu.tr. Yazarların ORCID Numarası: ${ }^{1}$ 0000-0002-2551-3860, ${ }^{2}$ 0000-0002-6619-9302, 0000-00030622-1106
} 
gerekli optimum aydınlanma miktarı standartlar çerçevesinde belirlenmiş ve sunulmuştur. Standartlar tarafından tavsiye edilen aydınlık düzeyi değerlerinin sağlanmaması görsel performansta düşüşe ve göz sağlığında risklere yol açabilmektedir [4]. Eğitim yapılan ortamlarda aydınlanma miktarının standartlarda belirtilen düzeyleri sağlaması gerekirken, yapay aydınlatma kullanımında düzgün bir dağılımın sağlanması ve kamaşmanın önlenmesi önemlidir [5]. TS EN 12665 standardında görsel konfor çevre tarafından uyarılarak oluşan görsel hoşluğun öznel hali olarak tanımlanmaktadır [6]. Aydınlanma performansı yanı sıra enerji tasarrufu açısından aydınlanma değerlendirildiğinde floresan aydınlanma ekipmanları ile karşılaştırıldığında LED tipi aydınlatma ekipmanlarının enerji verimliliklerinin daha yüksek olduğu bilinmektedir. LED ve floresan aydınlatma düzenine sahip 3 farklı sınıfta uygulaması gerçekleştirilen karşılaştırma çalışmasında, led aydınlatma düzenine sahip sınıflarda floresan ile aydınlatılan sınıflara göre \%58 daha az enerji sarfiyatı belirlenmiştir [7].

$\mathrm{Bu}$ çalışmanın amacı bir eğitim binasının aydınlanma performansının, enerji verimliliğinin belirlenmesi ve iyileştirme önerilerinin oluşturulmasıdır.

Dersliklerde gerekli aydınlanma ihtiyacının belirlenmesi sürecinde ışık akısı yöntemi ile gerçekleştirilen teorik inceleme EN 12464-1 standardına uygun şekilde yapılmıştır.

İç mekan oda endeksi k ortam boyutlarına bağlıdır ve denklem 1'deki gibi hesaplanabilir.

$$
k=\frac{e \times b}{(e+b) h}
$$

Denklem 1'de e iç mekan en ve b boy uzunluklarını ifade ederken h aydınlatma ekipmanın aydınlatılan yüzeye olan dik uzaklığını temsil etmektedir. İç mekânda sağlanması beklenen toplam ışık akısı miktarı denklem 2 ifadesi ile hesaplanabilir.

$$
\Theta=\frac{E_{0} \times e \times b}{\eta x m}
$$

Denklem 2'de yer alan $E_{o}$ aydınlatılması planlanan ortam için gerekli ortalama aydınlık düzeyini, $\eta$ kullanma faktörünü, m bakım faktörünü ifade etmektedir. Aydınlatılması planlanan ortam için gerekli ortalama aydınlık düzeyi EN 12464-1 standardında Tablo 1'de verildiği gibi belirtilmektedir.

Tablo 1. EN 12464-1 standardına göre eğitim verilen binalar için gerekli aydınlık düzeyleri.

\begin{tabular}{lllll}
\hline 6.2 & Educational buildings & & & \\
\hline Ref. no. & Type of interior, task or activity & $\bar{E}_{m}$ & UGR & $R_{\mathbf{L}}$ \\
& & Ix & - & - \\
6.2 .1 & Classrooms, tutorial rooms & 300 & 19 & 80
\end{tabular}

Kullanma faktörünü belirlemek üzere gerekli olan yüzey yansıtma faktörü değerleri [8], [9] ve [10] numaralı kaynaklardan tespit edilmiş ve Tablo 2'de verilmiştir.

Tablo 2. Ortalama yüzey yansıtma faktörü.

\begin{tabular}{|l|l|l|l|}
\hline \multirow{2}{*}{ Ortalama yansıtma faktörü (\%) } & $\begin{array}{l}\text { Tavan } \\
(\text { Beyaz })\end{array}$ & $\begin{array}{l}\text { Duvar } \\
(\text { Beyaz })\end{array}$ & $\begin{array}{l}\text { Çalışma düzlemi } \\
\text { (Koyu tonlu) }\end{array}$ \\
\cline { 2 - 4 } & 70 & 70 & 20 \\
\hline
\end{tabular}

Mevcut 4x18 W tüp floresan lambalı ve $33 \mathrm{~W}$ led panel armatür için kullanım faktörü değerleri Tablo 3’te verilmektedir. Değerler sektör tarafından sunulan armatür teknik verilerini içeren belgelerden oluşturulmuştur.

Tablo 3. Armatür kullanım faktörü.

\begin{tabular}{|l|l|l|l|l|l|l|l|l|l|l|}
\cline { 2 - 10 } \multicolumn{1}{c|}{} & \multicolumn{9}{|c|}{ Yüzey yansitma faktörü } & \multicolumn{2}{|c|}{ Oda indeksi (k) } \\
\cline { 2 - 11 } \multicolumn{1}{c|}{} & T & D & ÇD & 0,75 & 1 & 1,25 & 1,5 & 2 & 2,5 & 3 \\
\hline 4x18 W tüp floresan lambalı & 70 & 70 & 20 & 0,43 & 0,51 & 0,54 & 0,57 & 0,61 & 0,62 & 0,63 \\
\hline 33 W led panel & 70 & 70 & 20 & 0,45 & 0,53 & 0,57 & 0,59 & 0,63 & 0,64 & 0,65 \\
\hline
\end{tabular}


Aydınlatma ihtiyacı duyulan ortam için gerekli armatür sayısı n denklem 3'teki eşitlik ile belirlenir.

$n=\frac{\Theta}{\Theta_{o}}$

Denklem 3'te $\Theta_{o}$ her bir armatür için ışık akısı miktarını belirtmektedir.

\section{Materyal ve Yöntem}

Çalışma kapsamında bir eğitim kurumu dersliklerinde mevcut aydınlatma düzeyi UNI-T UT 383 mini dijital lüksmetre ve enerji tüketimi değerleri Fluke 435 marka enerji analizörü ile DIN EN 12464-1 standardına uygun şekilde gerçekleştirilen ölçümlemelerle belirlenmiştir. Kurumda aktif olarak kullanılan 10 adet derslik standart ölçülere sahiptir. Derslik düzenini örnekleyen görsel Şekil 1'de verilmektedir.

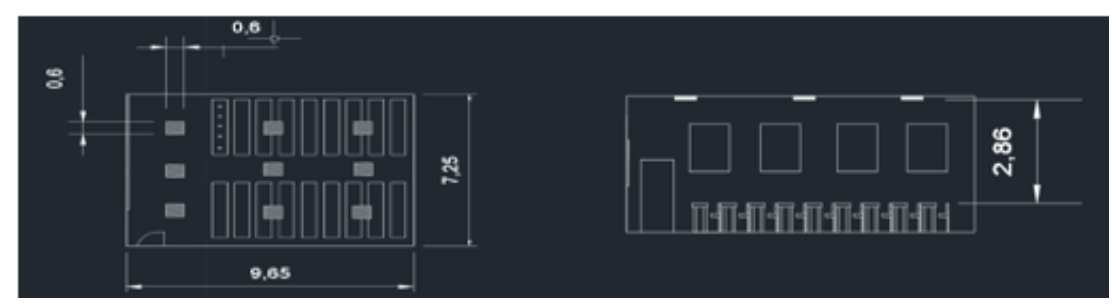

Şekil 1. Derslik düzeni ve boyutları.

Dersliklerde armatür ile öğrenci sıraları arası dik uzaklık 2,86 m’dir. Her bir sıra 5 öğrenci oturumu için düzenlenmiştir. 2 kolon şeklinde 9 sıra olmak üzere salonlar 90 kişiliktir. Sıra yüzeyleri 10 eş uzaklıktaki noktaya bölünerek her bir noktadan ölçümleme gerçekleştirilmiştir.

\section{Sonuçlar ve Tartışma}

Her bir derslik ve sıra düzeni için ortalama aydınlatma miktarı hesaplanarak Tablo 4'te verilmiştir.

Tablo 4. Derslik ortalama aydınlatma değerleri.

\begin{tabular}{|l|l|l|l|l|l|l|l|l|l|l|}
\hline \multicolumn{1}{|c|}{ Derslik } & $\mathbf{1}$ & $\mathbf{2}$ & $\mathbf{3}$ & $\mathbf{4}$ & $\mathbf{5}$ & $\mathbf{6}$ & $\mathbf{7}$ & $\mathbf{8}$ & $\mathbf{9}$ & $\mathbf{1 0}$ \\
\hline Sira 1 & 306.7 & 327 & 495.1 & 317.8 & 338.5 & 407.6 & 311 & 509.7 & 506 & 308.9 \\
\hline Sira 2 & 290 & 327 & 415.9 & 309 & 337.1 & 341.9 & 300 & 429.5 & 429.8 & 301.7 \\
\hline Sira 3 & 317.4 & 283 & 378.4 & 336.7 & 295.5 & 277.6 & 325.4 & 398.8 & 392.3 & 328.7 \\
\hline Sira 4 & 320 & 346.2 & 419.6 & 349.6 & 357.1 & 352.2 & 350.2 & 435.3 & 433.8 & 342.5 \\
\hline Sira 5 & 315 & 311 & 330.8 & 333.1 & 321.7 & 394 & 345.3 & 350.5 & 340.4 & 316.2 \\
\hline Sira 6 & 319.2 & 284.5 & 291 & 334.5 & 300.7 & 333.5 & 328.8 & 300.3 & 301.5 & 331 \\
\hline Sira 7 & 292.9 & 322.8 & 355.4 & 309.1 & 334.7 & 285.5 & 309.1 & 367.1 & 365.9 & 314.3 \\
\hline Sira 8 & 309.9 & 315.2 & 338 & 325.9 & 327 & 377.6 & 323.7 & 350.2 & 350.6 & 321 \\
\hline Sira 9 & 315.7 & 237.5 & 364.2 & 337.9 & 248.2 & 400.8 & 329.6 & 387.2 & 392.5 & 328.2 \\
\hline Ortalama & $\mathbf{3 0 9 . 6}$ & $\mathbf{3 0 6}$ & $\mathbf{3 7 6 . 4}$ & $\mathbf{3 2 8 . 1}$ & $\mathbf{3 1 7 . 8}$ & $\mathbf{3 5 2 . 3}$ & $\mathbf{3 2 4 . 7}$ & $\mathbf{3 9 2 . 0}$ & $\mathbf{3 9 0 . 3}$ & $\mathbf{3 2 1 . 3}$ \\
\hline
\end{tabular}

Alınan ölçümlemeler neticesinde DIN EN 12464-1 standardına göre sınıflarda gündüz saatleri için minimum 300 lux olması gereken aydınlatma düzeyinin mevcut 4x18 W tüp floresan lambalı armatürler ile sağlandığı 
belirlenmiştir. Yeterli aydınlık düzeyini minimum enerji tüketimi ile sağlayabilmek adına LED armatür tavsiyesinde bulunmak üzere mevcut aydınlatma panelleri enerji tüketimi açısından da değerlendirilmiştir. Mevcut durumda salonlarda günlük ortalama 8 saat olmak üzere yılda 9 ay aktif ders yapıldığı değerlendirilirse yıllık yaklaşık olarak 2160 saat aydınlatmalar aktiftir. Her bir sinıfta 8 adet 4x18 W tüp floresan lambalı armatür yer almaktadır. Floresan tüplü manyetik balastlı armatürlerin mevcut güç tüketim değerleri her bir sınıf için 12 saat süreçte ölçümlenmiş ve ortalama güç tüketimi değerleri Tablo 5 'te verilmektedir.

Tablo 5. Derslikler için mevcut floresan tüplü manyetik balastlı armatür güç tüketim değerleri.

\begin{tabular}{|c|l|l|l|l|l|l|l|l|l|l|}
\hline Derslik & 1 & 2 & 3 & 4 & 5 & 6 & 7 & 8 & 9 & 10 \\
\hline $\mathrm{W}$ & 581 & 583 & 579 & 581 & 585 & 581 & 583 & 585 & 578 & 583 \\
\hline
\end{tabular}

Sınıflar için seçilecek LED panel armatürler piyasada yaygın olarak kullanılan bir firmanın kataloglarından 33 W LED panel armatür olarak lümen değeri ve aydınlatma teknik verilerinde denklik sağlamak adına ve maliyetler göz önünde bulundurularak belirlenmiştir. Gerekli armatür sayılarını belirlemek için kullanılan veriler kataloglardan alınmıştır.

7,25 m x 9,65 m ölçülere sahip her bir sınıf için gerekli LED panel armatür sayısı Tablo 6' da verildiği şekliyle hesaplanmıştır.

Tablo 6. Led panel armatür sayısı

\begin{tabular}{|l|r|r|r|c|c|l|}
\hline $\mathrm{E}_{\mathrm{o}}, \operatorname{lux}$ & $\mathrm{k}$ & $\eta$ & $\mathrm{m}$ & $\Theta, \operatorname{lm}$ & $\Theta_{o}, \operatorname{lm}$ & $n$, adet \\
\hline 300 & 1,447 & 0,585 & 0,7 & 51254,5 & 3600 & $\mathbf{1 4 , 2 3}$ \\
\hline
\end{tabular}

Tablo 6' da belirlendiği üzere her bir sınıf için 15 adet 33 W LED panel armatür montajı ile 300 lux değerinde gerekli aydınlatma ihtiyacı sağlanabilir. LED armatürlerin montaj dahil birim fiyatı 130 TL'dir. Tablo 7'de mevcut armatürler ve alımı planlanan armatürler için yıllık enerji tüketimi miktarı hesaplanmış ve sağlanabilecek enerji tasarrufu miktarı belirlenmiştir. Gerçekleştirilen piyasa araştırması sonucu armatürlerin değişimi için gerekli yatırım miktarı belirlenmiş ve geri ödeme süresi hesaplanarak sunulmuştur.

Tablo 7. Yıllık enerji tüketimi, tasarruf miktarı, yatırım miktarı ve geri ödeme süresi.

\begin{tabular}{|l|l|l|l|}
\hline & $\begin{array}{l}\text { Yıllık enerji sarfiyatı (yıllık 2160 } \\
\text { çalışma saati) }\end{array}$ & $\begin{array}{l}\text { Yıllık enerji } \\
\text { maliyeti* }\end{array}$ & $\begin{array}{l}\text { Montaj dahil armatür değişim } \\
\text { maliyeti }\end{array}$ \\
\hline $\begin{array}{l}\text { 4x18 W tüp floresan lambalı } \\
\text { armatür }\end{array}$ & $18853,56 \mathrm{kWh}$ & $7827,99 \mathrm{TL}$ & \\
\hline $\begin{array}{l}33 \mathrm{~W} \text { LED panel armatür }(150 \\
\text { adet) }\end{array}$ & $10692 \mathrm{kWh}$ & $4439,31 \mathrm{TL}$ & $19500 \mathrm{TL}$ \\
\hline Enerji tasarrufu miktarı & $\mathbf{3 3 8 8 , 6 8}$ TL & \\
\hline Geri ödeme süresi (yıl) & $\mathbf{5 , 7 5}$ & & \\
\hline
\end{tabular}

Optimum düzeyde aydınlatma uygulamalarının minimum düzeyde enerji maliyetiyle sağlanması günümüz elektrik ve enerji sektörünün çalışma alanları arasındadır. Gelişen aydınlatma sistemi teknolojileri konfor, güvenlik, sağlık ve enerji maliyetlerini göz önünde bulundurarak aydınlatma ekipmanları geliştirirken, uygulama alanlarının özel şartlarına uygun sistem tasarımları göz önünde bulundurulmaktadır. Bu özel şartlar gerektiren alanlar arasında eğitim yapılan yapılarda girmektedir. Çalışma kapsamında aydınlatma düzeyi ölçümlenen bir eğitim kurumuna ait de4rslikler için uluslararası standartlarda belirtilen 300 lux aydınlatma gereksiniminin tüp floresan armatürler ile sağlandığı ancak mevcut armatürlerin enerji tüketimlerinin minimize edilebilmesi adına led armatür panel önerimi değerlendirildi. Gerçekleştirilen enerji ve ekonomik analiz çalışması ile led armatür montajı sağlanabilecek yıllık tasarruf miktarı $8161,56 \mathrm{kWh}$ olarak hesaplanmıştır. $19500 \mathrm{TL}$ tutarında led armatür yatırımıyla sağlanacak yıllık 3388,68 TL karşılığındaki enerji tasarrufu sayesinde 5,75 yıl içerisinde yatırım maliyetinin karşılanması öngörülmektedir. 


\section{Kaynaklar}

[1] Al-Khatatbeh BJ, Ma'bdeh SN. Improving visual comfort and energy efficiency in existing classrooms using passive daylighting techniques. Enrgy Proced 2017; 136: 102-108.

[2] Yağmur ŞA, Sözen MŞ. Dersliklerde görsel konfor ve iç yüzeylerin etkisi. Mageron 2016; 11(1): 49-52.

[3] Winterbottom M, Wilkins A. Lighting and discomfort in the classroom. J Environ Psychol 2009; 29: 63-75.

[4] Erdem L, Enarun D. Kullanıcıların aydınlık düzeyi tercihlerinin değiskenliği üzerine bir çalışma. IV. Ulusal Aydınlatma Sempozyumu ve Sergisi Programı; 13-15 Aralık 2007; İzmir. 1-7.

[5] Yener AK, Güvenkaya RK, Şener F. İlköğretim dersliklerinin görsel konfor açısından incelenmesi ve değerlendirilmesi. ITU Dergisi/a Mimarlık, Planlama, Tasarlama 2009; 8(1): 105-116.

[6] Yıldız Y. Dersliklerde günışığı performansının değerlendirilmesi: Balıkesir Üniversitesi örneği. 9. Ulusal Çatı \& Cephe Konferans1; 12-13 Nisan 2018; İstanbul. 1-8.

[7] Davis RG, Wilkerson A. Tuning the light in classrooms: evaluating trial led lighting systems in three classrooms at the carrollton-farmers branch independent school district in carrollton, tx. U.S. Department of Energy; Washington: Pacific Northwest National Laboratory. 1-30.

[8] Dahlan ND, Jones PJ, Alexander DK, Salleh E, Alias J. Evidence base prioritisation of indoor comfort perceptions in Malaysian typical multi-storey hostels. Buıld Environ 2009; 44: 2158-2165.

[9] Pless S, McBride M, Ornektekin O, Nicklas M, Jefferson P, Murphy J, Ryles M, Seibert K, ve diğerleri. Advanced energy design guide for k-12 school buildings. ASHRAE Design Guide; Atlanta: American Society of Heating, Refrigerating and Air-Conditioning Engineers. 1-234.

[10] Ibarra DI, Reinhart CF. Daylight factor simulations - how close do simulation beginners 'really' get?. Eleventh International IBPSA Conference; 27-30 Haziran 2009; Glasgow. 196-203. 